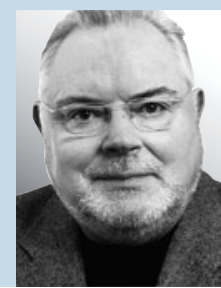

Dr. med.

Dieter Leithäuser

HNO-Arzt, Warburg

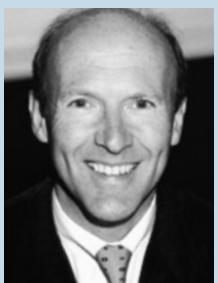

Prof. Dr. med.

Ralph Mösges

Universität Köln

\section{Adenoidektomie: Heiß gespült - Blutung gestoppt?}

\section{Längere Blutungen sind eine der Hauptkomplikationen bei Adenoidektomien. Ein Autorenteam testete, ob die Blutungen durch Spülen mit $50^{\circ}$ Celsius heißer Kochsalzlösung während des Eingriffs reduziert werden können.}

B ereits im 19. Jahrhundert wurde in Publikationen auf die blutungsstillende Wirkung von heißem Wasser aufmerksam gemacht. Neben Spülungen bei gynäkologischen Blutungen wurde heißes Wasser auch bei Epistaxis empfohlen. HNO-Ärzte wollten dem Effekt dieser Intervention nun in einer prospektiven, randomisierten Studie nachgehen. Sie nahmen 120 Kinder im Alter bis neun Jahre in ihre Untersuchung auf. Das Durchschnittsalter lag bei 4,5 Jahren.

Bei allen Studienteilnehmern führte der gleiche Operateur eine Adenoidektomie durch Kürettage durch. Nach vollständiger Entfernung der Adenoide wurde eine

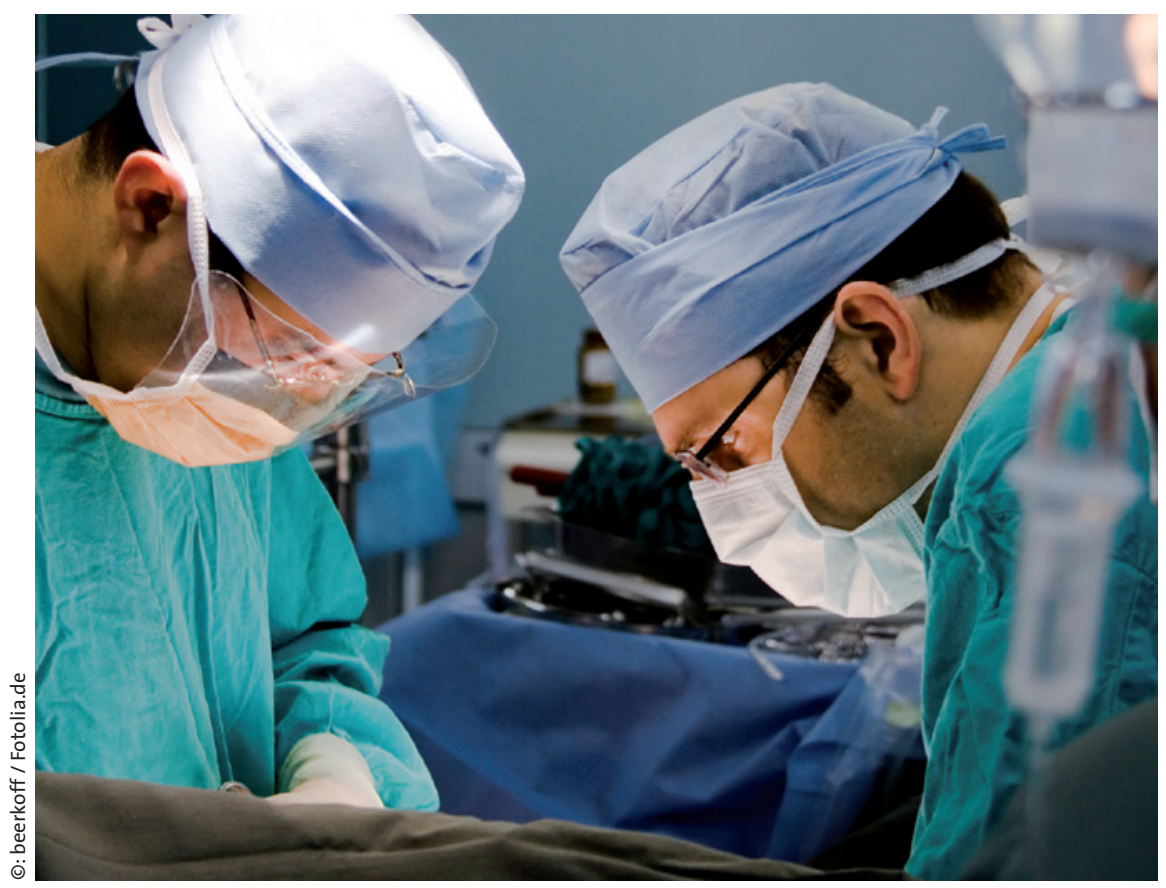

Spülungen mit heißem Wasser können Blutungen nach Adenoidektomien offensichtlich schneller zum Stillstand bringen.
Kompression des Nasopharynx über eine Minute vorgenommen. Im Anschluss erfolgte randomisiert eine Spülung des $\mathrm{Na}$ sopharynx entweder mit $50^{\circ}$ Celsius heißer Kochsalzlösung (Interventionsgruppe) oder mit $25^{\circ}$ Celsius warmer Lösung (Kontrollgruppe). Das Spülen wurde so lange fortgesetzt, bis die abgesaugte Flüssigkeit klar erschien. Die Spülung mit Kochsalzlösung galt als nicht effektiv, wenn sie über zehn Minuten andauerte oder mehr als ein Liter Flüssigkeit verwendet werden musste. In diesen Fällen führte der Operateur eine erneute Kürettage oder eine Elektrokauterisation durch.

Im Vergleich zur Kontrollgruppe fiel die Operationszeit bei Spülung mit $50^{\circ}$ Celsius heißer Kochsalzlösung um 3,1 Minuten kürzer aus. Dieser Unterschied war mit $\mathrm{p}=0,001$ signifikant. Auch die benötigte Zeit bis zur Blutstillung war um 1,8 Minuten signifikant reduziert $(\mathrm{p}=$ $0,008)$. Eine Rekürettage oder Elektrokauterisation war nur bei vier Patienten der Interventionsgruppe, jedoch bei zwölf Patienten der Kontrollgruppe notwendig. Es ergab sich keine Korrelation zwischen Größe der Adenoide, Indikationsstellung oder Geschlecht und der Dauer der Operation bzw. Blutstillung.

Fazit: Nach den Daten dieser Studie scheint es möglich, durch eine Spülung mit heißer Kochsalzlösung die Operations- und Blutungszeit bei Adenoidektomie zu verkürzen. 